\title{
Original
}

\section{Plasma $\beta$-thromboglobulin in Diabetes Mellitus in Relation to Vascular

\author{
Complications, Metabolic Control and Plasma Lipids*
}

\author{
Masaaki Eto**, Kiyoshi Watanabe**, Norihide Chonan**, \\ Yasunori IWASHIMA**, and Kaneo ISHII**
}

\section{Introduction}

The pathogenesis of both microangiopathy and macroangiopathy in diabetes mellitus is poorly understood. However, it seems widely accepted that multiple factors are involved, and abnormal platelet function ${ }^{1-5}$ ) may be one of these contributory factors.

$\beta$-thromboglobulin ( $\beta$-TG), a platelet specific protein is thought to be stored in platelet $\alpha$ granules, and to be released to the surrounding plasma during platelet aggregation ${ }^{6}$. An increase of plasma $\beta$-TG levels is regarded as a useful indicator of enhancement of in vivo platelet activation and release reaction. Thus, recently attention has been paid to the relationship between plasma $\beta$-TG levels and diabetes mellitus (particularly diabetic microangiopathy), but controversial data $^{7-17)}$ have been reported with regard to this relationship.

This study was undertaken to elucidate whether or not plasma $\beta$-TG levels correlate with diabetic vascular complications, metabolic control and plasma lipids.

\section{Patients and Methods}

Sixty-one diabetic patients attending the diabetic clinic at our medical college hospital were studied. Details of the sex ratio, age of the patients, duration

* This paper was presented at the 18 th meeting of the Japan Atherosclerosis Society in May 1986

** Second Department of Internal Medicine, Asahikawa Medical College, Nishikagura 4-5, Asahikawa 078, Japan

Received: January 26, 1987

Accepted: April 24, 1987 of diabetes, treatment, and state of metabolic control are shown in Table 1. They were made up of 7 type I diabetics and 54 type II diabetics. All of them were examined for the presence of fundal abnormalities following dilatation of the pupils. As a result, 18 of the 61 diabetics had no retinopathy, and 33 had background retinopathy, and 10 had proliferative retinopathy. Seven were diagnosed as having diabetic nephropathy since they had persistent proteinuria. One of the 7 patients had chronic renal failure presenting with plasma creatinine levels above $2.5 \mathrm{mg} / \mathrm{d} l$, but the rest had normal creatinine levels below $1.6 \mathrm{mg} / \mathrm{d} l$. These 7 patients with nephropathy had also retinopathy. In addition, 8 diabetics had macroangiopathy ( 2 with cerebral infarction alone, 3 with ischemic heart disease alone, 2 with ischemic heart disease and perivascular disease, and 1 with cerebral infarction and ischemic heart disease). Diagnosis of macroangiopathy was made according to the findings of ECG, angiography, or computed tomography. Two of these 8 patients had no microangiopathy.

Ten non-diabetics ( 7 males and 3 females, $49 \pm$ $5 \mathrm{yr}$ ), who were apparently healthy volunteers, were also studied.

Plasma $\beta$-TG was measured in platelet-poor plasma obtained and prepared as follows; $5 \mathrm{~m} l$ of blood obtained by venipuncture without occlusion were aspirated into a polystyrene syringe using a 20 -gauge needle. Blood samples were immediately transferred to cooled assay tubes containing an anticoagulant/antiplatelet mixture of Na EDTA and theophyllin. The tubes were mixed by gentle inversion, and cooled at $0-4^{\circ} \mathrm{C}$ in ice. Within the following 3 hours, the blood samples were cen- 
動脈硬化 Vol. 15 No.5 1987

Table 1 Characteristics of diabetics studied

\begin{tabular}{ccccc}
\hline Number $(\mathrm{M} / \mathrm{F})$ & \multicolumn{1}{c}{$\begin{array}{c}\text { Age } \\
(\mathrm{yr})\end{array}$} & $\begin{array}{c}\text { Duration } \\
(\mathrm{yr})\end{array}$ & $\begin{array}{c}\text { Fasting plasma } \\
\text { glucose }(\mathrm{mg} / \mathrm{d} l)\end{array}$ & $\begin{array}{c}\text { Hemoglobin } \mathrm{A}_{1} \\
(\%)\end{array}$ \\
\hline $61(34 / 27)^{*}$ & $57 \pm 2$ & $10.7 \pm 1.1$ & $145 \pm 6$ & $9.3 \pm 0.2$ \\
& $(25-77)^{* *}$ & $(1-26)^{* *}$ & $(81-320)^{* *}$ & $(6.8-14.0)^{*}$ \\
\hline
\end{tabular}

Values are means \pm SEM

*Fifteen of 61 patients were treated with diet, 16 were treated with oral agents, and 30 were treated with insulin

**Range

trifuged at $2,000 \mathrm{~g}$ for $30 \mathrm{~min}$ at $4^{\circ} \mathrm{C}$. The top $0.5 \mathrm{ml}$ of platelet-poor plasma were removed. Plasma $\beta$ TG levels were assayed by radioimmunoassay $(\beta$ thromboglobulin RIA kit, Radiochemical Center, Amersham, UK), based on the method of Ludlam et al. ${ }^{18)}$ Measurements were made twice, and the mean of the two values was considered as the final result.

Fasting plasma glucose, triglyceride and total cholesterol were also measured enzymatically on a sample of the blood drawn for $\beta$-TG. Similarly, HDL-cholesterol was measured by the $\mu l$-scale ultracentrifugation $^{19)}$, and hemoglobin $A_{1}$ was estimated by high pressure liquid chromatography (HLC-723GHb, Toyosoda Co., Tokyo).

Results were expressed as means \pm SEM. The difference in the mean values was analyzed by Student's $t$ test.

\section{Results}

Plasma $\beta$-TG levels were significantly $(\mathrm{p}<0.001)$ higher in diabetics as a group $(86 \pm 8 \mathrm{ng} / \mathrm{ml})$ than in non-diabetics $(42 \pm 3 \mathrm{ng} / \mathrm{ml})$. As shown in Table 2, there was no significant correlation between plasma $\beta$-TG levels and the age of the patients, duration of diabetes, fasting plasma glucose levels, and hemoglobin $A_{1}$. In addition, plasma $\beta$-TG levels did not correlate with plasma triglyceride, total cholesterol and HDL-cholesterol levels.

The association of plasma $\beta$-TG levels with diabetic vascular complications was also analyzed as shown in Table 3. No significant difference was noted in plasma $\beta$-TG levels between diabetics with and without retinopathy (mean 85 vs. $89 \mathrm{ng} / \mathrm{ml}$ ). No difference was also noted between diabetics with background retinopathy and those with proliferative retinopathy. The diabetics with nephropathy had higher levels of plasma $\beta$-TG than those without nephropathy (mean 112 vs. $80 \mathrm{ng} / \mathrm{ml}$ ), but this difference was not statistically significant.
Table 2 Correlation between plasma $\beta$-thromboglobulin levels and age, duration of diabetes, diabetic controls and plasma lipids

\begin{tabular}{lcc}
\hline \multicolumn{1}{c}{ Parameters } & $\mathrm{R}$ & Significance \\
\hline Age & -0.142 & NS \\
Duration & -0.115 & NS \\
Fasting plasma glucose & -0.054 & NS \\
Hemoglobin A & -0.087 & NS \\
Triglyceride & -0.169 & NS \\
Total cholesterol & 0.110 & NS \\
HDL-cholesterol & 0.008 & NS \\
\hline
\end{tabular}

NS; not significant $\mathrm{n}=61$

Table 3 Plasma $\beta$-thromboglobulin levels in diabetics with and without vascular complications

\begin{tabular}{lccc}
\hline Diabetics & Number & $\begin{array}{c}\beta \text {-thromboglobulin } \\
(\mathrm{ng} / \mathrm{m} l)\end{array}$ & Significance* \\
\hline $\begin{array}{l}\text { Retinopathy } \\
\text { without }\end{array}$ & 18 & $89 \pm 12(26-205)$ & \\
$\begin{array}{l}\text { with } \\
\text { w }\end{array}$ & 83 & $85 \pm 9(9-242)$ & NS \\
$\begin{array}{l}\text { Nephropathy } \\
\text { without }\end{array}$ & 54 & $80 \pm 8(9-205)$ & \\
$\begin{array}{l}\text { with } \\
\text { Macroangiopathy }\end{array}$ & $112 \pm 30(41-242)$ & NS \\
$\begin{array}{l}\text { without } 53 \\
\text { with }\end{array}$ & $89 \pm 9(9-242)$ & \\
\hline
\end{tabular}

Values are means \pm SEM

The range of the values is given in parentheses *between diabetics with and without complications NS; not significant

The one patient with elevated plasma creatinine levels $(2.7 \mathrm{mg} / \mathrm{d} l)$ showed the highest level of plasma $\beta$-TG $(242 \mathrm{ng} / \mathrm{m} l)$.

The diabetics with macroangiopathy showed a decreased tendency for plasma $\beta$-TG as compared with those without macroangiopathy (mean 64 vs. $89 \mathrm{mg} / \mathrm{d} l$ ).

Finally, plasma $\beta$-TG levels did not differ among the different types of treatment, types of diabetes or sex. 


\section{Discussion}

The present study confirmed that diabetics have increased values of plasma $\beta$-TG as compared with non-diabetics. This increase in diabetics seems widely accepted by many investigators $8,10,12,13,17)$.

In our data there was no significant difference in plasma $\beta$-TG levels between diabetics with and without retinopathy. Controversial data have been reported with regard to the relationship between plasma $\beta$-TG and diabetic retinopathy. Some investigators $7,10,16,17)$ did not observe a significant difference between diabetics with and without retinopathy. Our data support these findings. By contrast, others ${ }^{9,13,15)}$ found significantly higher levels of plasma $\beta$-TG in diabetics showing retinopathy (microangiopathy) than those without microangiopathy. Furthermore, Schernthaner et al. ${ }^{12)}$ reported a tendency for higher $\beta$-TG values connected with progressing stages of diabetic retinopathy. Thus, they emphasized the important role of enhanced platelet activation in the pathogenesis of diabetic retinopathy. In fact, platelet aggregates were observed in the retinal cappilaries in some diabetics ${ }^{1)}$. However, the reason for these discrepancies is obscure.

The present data revealed that diabetics with nephropathy had a tendency for higher levels of plasma $\beta$-TG. In addition, only the one patient with chronic renal failure (creatinine $2.7 \mathrm{mg} / \mathrm{d} l$ ) had highest level of plasma $\beta$-TG. These findings may be explained by the data of Schernthaner et al. ${ }^{12)}$ and Kurihara et al. ${ }^{16)}$, who found that an increase of plasma $\beta$-TG in diabetics with renal failure reflects merely the result of reduced renal elimination of $\beta$-TG. Thus, this increase seems secondary to impaired renal function, but not to be important in the pathogenesis of diabetic nephropathy.

Plasma $\beta$-TG levels were rather lower in diabetics with macroangiopathy than those without macroangiopathy. Only a few data have been reported concerning this point. Betteridge et al. ${ }^{13}$ ) found no significant difference in $\beta$-TG levels between diabetics with and without macroangiopathy. An increase of $\beta$-TG in acute phase of cerebral infarction ${ }^{18)}$ or myocardial infarction ${ }^{20}$ ) has been reported as well. Thus, $\beta$-TG seems not to play an important role in the chronic phase of macroangiopathy in diabetics.

Plasma $\beta$-TG levels did not correlate with the age, duration of diabetes, sex and types of therapy or diabetes, which agree well with the previous reports $^{7,8,10,13,17)}$. On the other hand, the association of $\beta$-TG values with diabetic control seems complicated. We did not find this association, in agreement with the reports of the previous authors $7,8,10,12,13,15,17)$. By contrast, an increase of $\beta$-TG in newly diagnosed diabetic patients ${ }^{8,9)}$ or in poorly controlled diabetics ${ }^{16)}$ has been reported. Burrow et al. ${ }^{9)}$ found that higher $\beta$-TG in newly diagnosed diabetics had fallen to normal levels after treatment.

It has been reported that plasma lipid levels correlate with $\beta$-TG levels in diabetics ${ }^{13)}$ or nondiabetics $^{21}$. It is likely that increased levels of lipids alter the composition of platelet membrane, and lead to enhanced platelet activation related to release reaction. However, we did not observe this correlation.

From the present results, it is concluded that plasma $\beta$-TG levels are at least elevated in diabetics although their levels did not correlate with diabetic microangiopathy, control, and plasma lipid levels. The significance and cause of this elevation in diabetics are not known. One explanation is that it is the result of diffuse changes in the diabetic vascular endothelium, which might lead to abnormal platelet function. Another explanation is that the platelets or plasma in diabetics have the primary defects. It is possible that these changes in endothelium or defects of the platelets or plasma might exist early before the vascular lesions become clinically detectable, and thus the association of plasma $\beta$-TG with vascular complications could not be established, as reported here.

However, some investigators found a close association of plasma $\beta$-TG levels with diabetic complications, control or plasma lipid levels. The reasons for the controversial results is unclear. Technical difficulties (blood sampling and RIA for the determination of $\beta$-TG) ${ }^{15)}$ may be raised as a reason. Thus, further data should be accumulated after this problem has been resolved. In addition, the significance of $\beta$-TG in plasma should be reevaluated. Only plasma $\beta$-TG levels may not always reflect platelet function in diabetes. It is necessary that we evaluate platelet function in diabetes generally not only with plasma $\beta$-TG but also with other parameters reflecting in vivo platelet function, and then conclude these associations described above. 


\section{References}

1) Bloodworth, J. M., Jr. and Molitor, D. L.: Ultrastructural aspects of human and canine diabetic retinopathy. Invest. Ophthalmol., 4: 1037-1048 (1965).

2) Heath, H., Brigden, W. D., Canever, J. V., Pollock, J., Hunter, P. R., Kelsey, J. and Bloom, A.: Platelet adhesiveness and aggregation in relation to retinopathy. Diabetologia, 7: 308-315 (1971).

3) Kwaan, H. C., Colwell, J. A., Cruz, S., Suwanwela, N. and Dobbie, J. G.: Increased platelet aggregation in diabetes mellitus. J. Lab. Clin. Med., 80: 236-246 (1972).

4) O’Malley, B. C., Timperley, W. R., Ward, J. D., Porter, N. R. and Preston, F. E.: Platelet abnormalities in diabetic peripheral neuropathy. Lancet, 2: 1274-1276 (1975).

5) Ross, R. and Glomset, J. A.: The pathogenesis of atherosclerosis. N. Engl. J. Med., 295: 420-425 (1975).

6) Moore, S., Pepper, D. S. and Cash, J. D.: The isolation and characterization of a platelet specific $\beta$-globulin ( $\beta$-thromboglobulin) and the detection of anti-urokinase and anti-plasmin released from thrombin-aggregated washed human platelets. Biochim. Biophys. Acta, 379: 360-369 (1975).

7) Campbell, I. W., Dawes, J., Fraser, D. M., Pepper, D. S., Clarke, B. F., Duncan, L. J. P. and Cash, J. D.: Plasma $\beta$-thromboglobulin in diabetes mellitus. Diabetes, 26: 1175-1177 (1977).

8) Burrows, A. W., Chavin, S. I. and Hockaday, T. D. R.: Plasma-thromboglobulin concentrations in diabetes mellitus. Lancet, 1: 235-237 (1978).

9) Preston, F. E., Ward, J. D., Marcola, B. H., Porter, N. R. and Timperley, W. R.: Elevated $\beta$ thromboglobulin levels and circulating platelet aggregates in diabetic microangiopathy. Lancet, 1: 238-240 (1978).

10) Borsey, D. Q., Dawes, J., Fraser, D. M., Prowse, C. V. Elton, R. A. and Clarke, B. F.: Plasma betathromboglobulin in diabetes mellitus. Diabetologia, 18: 353-357 (1980).

11) Janka, H. U., Standl, E. and Mehnert, H.: Increased platelet adenylate cyclase activity in diabetic patients with microangiopathy. Horm. Metab. Res., 11 (Suppl.): 26-29 (1981).

12) Schernthaner, G., Sinzinger, H., Silberbauer, K.,
Freyler, H., Mühlhauser, I. and Kaliman, J.: Vascular prostacyclin, platelet sensitivity to prostaglandins and platelet-specific proteins in diabetes mellitus. Analysis of type of diabetes, state of metabolic control and diabetic microangiopathy. Horm. Metab. Res., 11 (Suppl.): 33-43 (1981).

13) Betteridge, D. J., Zahavi, J., Jones, N. A. G., Shine, B., Kakkara, V. V. and Galton, D. J.: Platelet function in diabetes mellitus in relationship to complications, glycosylated haemoglobulin and serum lipoproteins. Eur. J. Clin. Invest., 11: 273277 (1981).

14) Janka, H. U., Standl, E., Schramm, W. and Mehnert, H.: Platelet enzyme activities in diabetes mellitus in relation to endothelial damage. Diabetes, 32 (Suppl. 2): 47-51 (1983).

15) Nakai, T., Arai, H. and Yamada, R.: Plasma $\beta$ thromboglobulin levels in diabetic microangiopathy. J. Japan Diab. Soc., 22: 1083-1090 (1979) (in Japanese).

16) Kurihara, Y., Nakayama, H., Oda, K. and Nakagawa, S.: Plasma $\beta$-thromboglobulin and plasma platelet factor 4 in diabetes mellitus. J. Japan Diab. Soc., 23: 661-668 (1980) (in Japanese).

17) Kitazawa, A., Yoritsune, H., Takamatsu, J., Nakata, K., Furukawa, K., Fujita, K. and Mozai, T.: Plasma $\beta$-thromboglobulin levels in diabetes mellitus-The influence of age-. J. Japan Diab. Soc., 25: 113-118 (1982) (in Japanese).

18) Ludlam, C. A., Moore, S., Bolton, A. E., Pepper, D. S. and Cash, J. D.: The release of a human platelet specific protein measured by a radioimmunoassay. Thrombo. Res., 6: 543- 548 (1975).

19) Eto, M., Watanabe, K., Iwashima, Y., Morikawa, A., Takebe, T. and Ishii, K.: Elevation of plasma high density lipoprotein-cholesterol in spontaneously diabetic Chinese hamsters. Tohoku J. Exp. Med., 144: 281-290 (1984).

20) Denham, M. J., Fisher, M., James, G. and Hassan, M.: $\beta$-thromboglobulin and heparin-neutralising activity test in clinical conditions. Lancet, 1: 11531154 (1977).

21) Zahavi, J., Betteridge, J. D., Jones, N. A., Galton, D. J. and Kakkar, V. V.: Enhanced in vivo platelet release reaction and malondialdehyde formation in patients with hyperlipidemia. Am. J. Med., 70: 59-64 (1981). 


\section{Summary}

The aim of this study is to elucidate whether or not plasma $\beta$-thromboglobulin ( $\beta$-TG), an indicator of in vivo platelet activation and release reaction, is related to diabetic vascular complications, state of metabolic control and plasma lipids. $\beta$-TG was measured using Amersham RIA kit. Sixty-one diabetic patients were studied. Plasma $\beta$-TG levels were elevated in diabetics $(86 \pm 8 \mathrm{ng} /$ $\mathrm{m} l$ ). There was no significant correlation between plasma $\beta$-TG levels and the age, duration of diabetes, fasting plasma glucose levels, hemoglobin $A_{1}$, and plasma lipid levels. In addition, plasma $\beta$-TG levels did not differ among the different types of treatment or types of diabetes or sex.

No significant difference was noted in plasma $\beta$-TG levels between diabetics with and without retinopathy. The diabetics with nephropathy had higher levels of plasma $\beta$-TG than those without nephropathy. The diabetics with macroangiopathy showed a decreased tendency for plasma $\beta$-TG values as compared with those without macroangiopathy. However, these differences did not reach statistical significance.

It is concluded that diabetics had higher levels of plasma $\beta$-TG, suggesting abnormal platelet function, i.e. its hyperaggregability in diabetes, but that plasma $\beta$-TG levels are not related to diabetic vascular complications, metabolic control and plasma lipid levels. Further studies will be required to clarify the significance and cause of its higher levels in diabetes mellitus.

Key words: $\beta$-thromboglobulin, diabetes mellitus, vascular complications, metabolic control, lipids. 